\title{
Short-lasting unilateral neuralgiform headache attacks with cranial autonomic symptoms in NMOSD
}

Yuri Mizuno, MD, Koji Shinoda, MD, PhD, Mitsuru Watanabe, MD, PhD, Takuya Matsushita, MD, PhD, Ryo Yamasaki, MD, PhD, and Jun-ichi Kira, MD, PhD

Neurol Neuroimmunol Neuroinflamm 2018;5:e447. doi:10.1212/NXI.0000000000000447

Neuromyelitis optica spectrum disorder (NMOSD) is an autoimmune demyelinating disorder of the CNS that frequently affects brainstem functions. ${ }^{1}$ Trigeminal neuralgia occurs in $2.5 \%$ of patients with $\mathrm{NMOSD}^{1}$; however, the occurrence of trigeminal autonomic cephalalgia (TAC) is rarely reported. ${ }^{2,3}$ Here, we describe a case of NMOSD with anti-aquaporin-4 (AQP4) antibodies who had a relapse with brainstem and cervical spinal cord lesions manifesting as short-lasting unilateral neuralgiform headache attacks with cranial autonomic symptoms (SUNA), a rare form of TAC.

\section{Case report}

A 55-year-old woman developed intractable hiccups and vomiting that lasted for 1 month. Three weeks after the onset, she noticed dysesthesia in her upper extremities and was referred to our hospital. Neurologic examination revealed red desaturation in both eyes, despite normal visual acuity and pupillary reflexes, positive Lhermitte sign, and bilateral dysesthesia at the C8Th1 dermatomes. Serum anti-AQP4 antibodies were positive by a cell-based assay. MRI revealed a longitudinally extensive spinal cord lesion encompassing 3 vertebral segments from C7 to Th2 spine levels. She was diagnosed as having NMOSD and treated with intravenous methylprednisolone (IV-MP, $1,000 \mathrm{mg} / \mathrm{d}$ for 3 days). Plasmapheresis was also performed because of the suboptimal effects of IV-MP on dysesthesia. To prevent relapses, oral prednisolone therapy was initiated at $30 \mathrm{mg} / \mathrm{d}$, which was gradually tapered and maintained at 11 $\mathrm{mg} / \mathrm{d}$ until the second attack.

At 57 years of age, she developed intermittent, 1-3-minute-lasting severe, tingling, and stabbing pain around the left eye, constantly accompanied by ipsilateral rhinorrhea and lacrimation 5-20 times a day. A facial photograph during a headache attack is presented in figure, A. This pain was inducible by stimulation of the left side of her face without any cessation after each attack, and it was refractory to oral loxoprofen, ibuprofen, indomethacin, and carbamazepine. Neurologic examination revealed only mild hypoalgesia on the left side of her face during the remission of headache. Surprisingly, brain MRI revealed new T2hyperintense lesions in the left dorsolateral medulla oblongata and left dorsal cervical spinal cord at the $\mathrm{C} 1 / 2$ spine level (figure, B and C). Gadolinium-enhancement was observed in the cervical cord lesion (figure, D). Three-dimensional double inversion recovery images clearly showed hyperintense lesions (figure, E-H). We diagnosed her as having SUNA with a relapse of NMOSD. IV-MP $(1,000 \mathrm{mg} / \mathrm{d}$ for 3 days $)$ and oral lamotrigine $(25 \mathrm{mg} / \mathrm{d})$ were initiated 10 days after the onset. Headache attacks began to decrease after the initiation of treatment. Subsequently, the dose of lamotrigine was increased to $75 \mathrm{mg} / \mathrm{d}$, and a second course of IVMP was performed based on the insufficient treatment response. Headache attacks

\author{
Correspondence \\ Dr. Kira \\ kira@neuro.med.kyushu-u.ac.jp
}



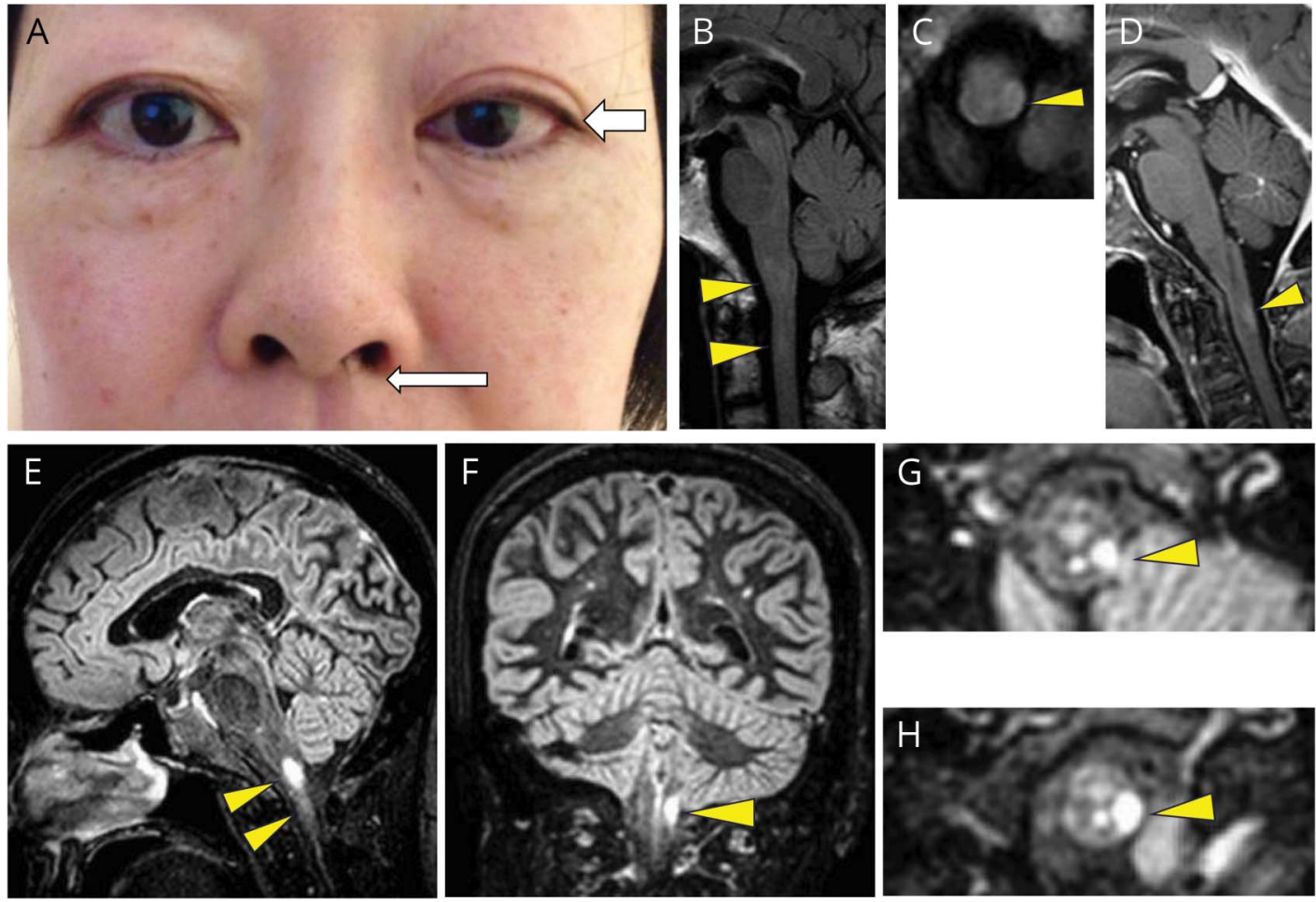

(A) Facial photograph during headache attack showing rhinorrhea and lacrimation on the left side (arrows). Written informed consent was obtained to show part of the face without masking. (B) Sagittal fluid-attenuated inversion recovery (FLAIR), (C) an axial FLAIR image at the level of the lower medulla oblongata and (D) gadolinium-enhanced T1-weighted images of the brain. Three-dimensional double inversion recovery images in sagittal (E), coronal (F), and axial planes ( $G$, medulla oblongata; $H$, lower medulla oblongata). Arrowheads indicate lesions.

disappeared completely 21 days after the onset. Oral tacrolimus $(3 \mathrm{mg} / \mathrm{d})$ was added to prevent further relapses. Thereafter, she has not suffered any recurrence for 10 months.

\section{Discussion}

We described a case of NMOSD with anti-AQP4 antibodies, who had a relapse manifesting as SUNA. SUNA and short-lasting unilateral neuralgiform headache with conjunctival injection and tearing (SUNCT) are rare forms of TAC. ${ }^{4}$ SUNA is defined as having only one or neither of conjunctival injection or lacrimation, whereas SUNCT is defined as having both symptoms. The occurrence of SUNA/SUNCT is rare and was reported only twice previously. ${ }^{2,3}$ A longitudinal brainstem lesion caused SUNCT in a patient with Devic syndrome without reference to anti-AQP4 antibodies; however, axial distribution of the medullary lesion was not shown. ${ }^{2}$ The occurrence of unilateral TAC, probably SUNCT, was also described in a patient with NMOSD with anti-AQP4 antibodies who developed a lesion at the center of the medulla oblongata. ${ }^{3}$ Our case clearly had a left dorsolateral medulla oblongata lesion, which included the left spinal nucleus of the trigeminal nerve that corresponded with the left side SUNA.
Furthermore, the lesion responsible for SUNA in our patient confirms a report of infarction in the right dorsal medulla oblongata, which caused SUNCT. ${ }^{5}$

SUNA/SUNCT is highly refractory to medication. Antiepileptic drugs or corticosteroids and surgical treatment are used to suppress SUNA/SUNCT. Of these, a good-to-excellent response to lamotrigine was observed in $11 / 19$ cases $(58 \%)$ of SUNA/SUNCT. ${ }^{6}$ Likewise, another study reported that lamotrigine was effective in $4 / 5$ SUNCT cases $(80 \%){ }^{7}$ Indeed, in our patient, where SUNA was refractory to oral loxoprofen, diclofenac, indomethacin, and carbamazepine, the use of lamotrigine and IV-MP successfully alleviated SUNA attacks. The association of TAC including SUNA with NMOSD was suggested by the treatment response and the clearly visualized ipsilateral dorsal medulla lesion, compatible as a causative lesion of SUNA/SUNCT. We propose that neurologists should be aware that SUNA/SUNCT could be the sole brainstem manifestation of NMOSD and a combination of immunotherapies and lamotrigine should be considered for such cases.

\section{Author contributions}

Dr. Mizuno treated the patient and drafted the manuscript. Dr. Shinoda treated the patient and drafted/revised the manuscript. Dr. Watanabe treated the patient. Dr. Matsushita 
and Dr. Yamasaki drafted/revised the manuscript. Dr. Kira supervised the treatment and manuscript writing.

\section{Study funding}

This study was supported in part by a Health and Labour Sciences Research Grant on Intractable Diseases (H26Nanchitou (Nan)-Ippan-043) from the Ministry of Health, Labour and Welfare, Japan, a Grant-in-Aid for Scientific Research A (MEXT KAKENHI Grant No. 16H02657) and C (15K09341), and a Grant-in-Aid for Young Scientists B (17K16124, 17K16125) from the Japan Society for the Promotion of Science, Japan.

\section{Disclosure}

Y. Mizuno reports no disclosures. K. Shinoda received speaker honoraria from Takeda Pharmaceutical and Biogen and received research support from the Japanese Multiple Sclerosis Society and Japan Intractable Disease Research Foundation. M. Watanabe received research support from GSK Japan and the Japan Society for the Promotion of Science. T. Matsushita received speaker honoraria from Bayer-Schering, Mitsubishi Tanabe, Biogen, and Takeda Pharmaceuticals and received research support from the Japan Society for the Promotion of Science. R. Yamasaki reports no disclosures. J.-i. Kira received travel funding from Bayer and Biogen; served on the editorial board of Multiple Sclerosis, BMC Medicine, Journal of the Neurological Sciences, Multiple Sclerosis and Related Disorders, PLoS One, Acta Neuropathologica Communications, and Clinical and Experimental Neuroimmunology; and received research support from the Ministry of Health, Labour, and Welfare, Japan, and Japan Agency for Medical Research and Development; Grant-in-Aid. Full disclosure form information provided by the authors is available with the full text of this article at Neurology.org/NN.

Received October 21, 2017. Accepted in final form January 5, 2018.

\section{References}

1. Kremer L, Mealy M, Jacob A, et al. Brainstem manifestations in neuromyelitis optica: a multicenter study of 258 patients. Mult Scler 2014;20:843-847.

2. Kursun O, Arsava EM, Oguz KK, Tan E, Kansu T. SUNCT associated with Devic's syndrome. Cephalalgia 2006;26:221-224.

3. Mathew T, Nadimpally US, Sarma GR, Nadig R. Trigeminal autonomic cephalalgia as a presenting feature of Neuromyelitis Optica: "A rare combination of two uncommon disorders". Mult Scler Relat Disord 2016;6:73-74.

4. Headache Classification Committee of the International Headache Society. The international classification of headache disorders, 3rd edition (beta version). Cephalalgia 2013;33:629-808.

5. Lambru G, Trimboli M, Tan SV, Al-Kaisy A. Medullary infarction causing coexistent SUNCT and trigeminal neuralgia. Cephalalgia 2017;37:486-490.

6. Williams MH, Broadley SA. SUNCT and SUNA: clinical features and medical treatment. J Clin Neurosci 2008;15:526-534.

7. D'Andrea G, Granella F, Ghiotto N, Nappi G. Lamotrigine in the treatment of SUNCT syndrome. Neurology 2001;57:1723-1725. 


\title{
Neurology $^{\odot}$ \\ Neuroimmunology \& Neuroinflammation
}

\author{
Short-lasting unilateral neuralgiform headache attacks with cranial autonomic \\ symptoms in NMOSD \\ Yuri Mizuno, Koji Shinoda, Mitsuru Watanabe, et al. \\ Neurol Neuroimmunol Neuroinflamm 2018;5; \\ DOI 10.1212/NXI.0000000000000447
}

This information is current as of February 21, 2018

\section{Updated Information \& Services}

References

Subspecialty Collections

Permissions \& Licensing

Reprints including high resolution figures, can be found at: http://nn.neurology.org/content/5/3/e447.full.html

This article cites 7 articles, 0 of which you can access for free at: http://nn.neurology.org/content/5/3/e447.full.html\#\#ref-list-1

This article, along with others on similar topics, appears in the following collection(s):

All Demyelinating disease (CNS)

http://nn.neurology.org//cgi/collection/all_demyelinating_disease_cns All Headache

http://nn.neurology.org//cgi/collection/all_headache

MRI

http://nn.neurology.org//cgi/collection/mri

Optic neuritis; see Neuro-ophthalmology/Optic Nerve

http://nn.neurology.org//cgi/collection/optic_neuritis

Information about reproducing this article in parts (figures,tables) or in its entirety can be found online at:

http://nn.neurology.org/misc/about.xhtml\#permissions

Information about ordering reprints can be found online:

http://nn.neurology.org/misc/addir.xhtml\#reprintsus

Neurol Neuroimmunol Neuroinflamm is an official journal of the American Academy of Neurology.

Published since April 2014, it is an open-access, online-only, continuous publication journal. Copyright

Copyright $\odot 2018$ The Author(s). Published by Wolters Kluwer Health, Inc. on behalf of the American

Academy of Neurology.. All rights reserved. Online ISSN: 2332-7812.

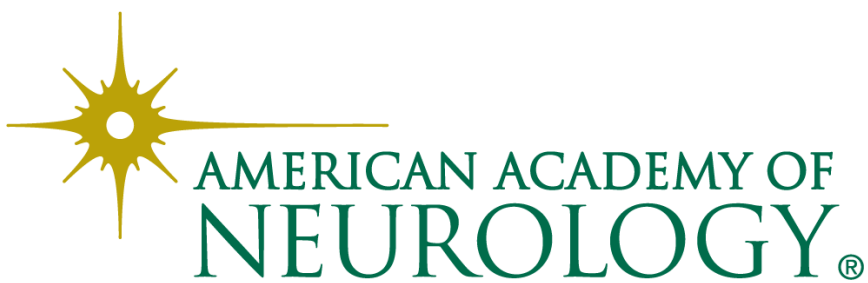

